\title{
Treatment of Open Comminuted Diaphyseal Fracture of the Tibia by Ilizarov Hany Zaki Saied ${ }^{1}$, Wael Shaaban Mahmoud ${ }^{1}$ Kareem Samir Arafa $^{2}$
}

${ }^{1}$ Orthopaedic Surgery Faculty of Medicine for girls Al-azhar University, ${ }^{2}$ Faculty of Medicine, Al-azhar University *Corresponding author: Kareem Samir Arafa, Email: drkareemgms@ gmail.com, Mobile: (+20) 1003252480

\begin{abstract}
Background: Management of open diaphyseal tibial shaft fractures can be comminuted due to lack of soft tissue coverage and blood supply of the tibial shaft. Open reduction and internal fixation [ORIF] with plates and screws achieves stability, allows joint mobilization but does not allow early weight bearing which as a stimulus is a must for early union. Closed reduction and intramedullary fixation compromise the intramedullary blood supply and increases the risk of infection in open fractures. Ilizarov is considered safe in treating these open injuries, at the same time it has the advantages of easy application, minimal invasive, and convenient subsequent soft tissue repair. Objective: The aim of current study was to evaluate treatment of open comminuted diaphyseal tibial fracture by ilizarov external fixator; its effective, availability, outcomes and complications.

Patients and Methods: This prospective study included a total of 10 patients with comminuted tibial diaphyseal fractures managed with early Ilizarov external fixator, attending at Alharam Hospital. This study was conducted between Feb 2018 and July 2019. General assessment indicators included pain, complete union, deformity in comparison to healthy limb, infection, leg limb discrepancy, stiffness and activity of the patients were analysed.

Results: Follow-up of all participants for analysis was done. The follow-up time was 17 months. Three cases developed ankle stiffness. The average total range of knee motion in our cases was 130.5 (range 125-140). A significant limp occurred only in 3 cases. NO persistent limp persisted in our cases. Fifteen patients had minimal pain at the site of fracture. Signicant pain occurred in three cases. Pin site infection occurred in 7 patients. All the patients achieved full union and activity. Excellent results were obtained in 4 cases (40\%). Good results were obtained in 3 cases (30\%) with overall good to excellent results were about (70\%). Fair results were obtained in 3 cases $(30 \%)$.
\end{abstract}

Conclusion: It could be concluded that the Ilizarov external fixator is a golden horse for orthopedic surgeons. It holds wonderful promise in the management of open diaphyseal tibial shaft fractures.

Keywords: open diaphyseal tibia, Ilizarov tibia comminuted fractures.

\section{INTRODUCTION}

Tibial fractures are the most common long bone fractures, with around $25 \%$ being open fractures. The majority of open comminuted diaphyseal tibial fractures result from high velocity trauma such as road traffic accidents and falls from height. management of open diaphyseal tibial shaft fractures can be comminuted due to lack of soft tissue coverage and blood supply of the tibial shaft ${ }^{[1]}$ .Prognosis depends on displacement, comminution, and soft tissue injury. Advanced bone reconstruction and soft tissue coverage is required to poses bone and soft tissue healing. Thus, the rate of complications associated with open comminted diaphyseal tibial fractures is high ${ }^{[1]}$. When conservative treatment is inappropriate, several methods of surgical management can be used ${ }^{[2]}$.Open reduction and internal fixation [ORIF] with plates and screws achieves stability, allows joint mobilization but does not allow early weight bearing which as a stimulus is a must for early union [3] .Minimally invasive percutaneous plate osteosynthesis [MIPPO], shows high rate of healing and low rate of soft-tissue complications. Close reduction and intramedullary nailing saves extra osseous blood supply, doesn't disturb fracture hematoma and maintains soft tissue envelope, allows early weight bearing ${ }^{[4]}$, but it compromises the intramedullary blood supply and in open fractures increases the risk of infection ${ }^{[5]}$.
External fixators have been used for fracture treatment. Since the introduction of the Ilizarov method, these fixators have gained the widespread use ${ }^{[6]}$. However, the basic principles of fixation techniques have not been changed, although intensive technologic developments have been recorded. Even though the circular fixators are not the first choice for the treatment of simple fractures. They are often preferred for complex fractures associated with soft tissue damage. One of the greatest cones of the circular fixators are their application to various traumatic extremities with a reduction in infection rates. The most important disadvantages of the method are patient psychological trauma during the follow up, patient compliance modifications are needed, and external fixation devices are more difficult to learn compared to other methods of fixation ${ }^{[6]}$. Frequent need for secondary operations, prolonged healing duration and pin site infections are ingrained problems in external fixation ${ }^{[7]}$.Ilizarov has revolutionized the management of open comminuted diaphyseal tibial fractures which are more susceptible to the infection by allowing more union rates and early mobilization of the extremity and other advantages which include wound management, and deformity correction and limb lengthening, among others. The tensioned wire 
circular fixator has proved valuable in subacute and acute treatment of tibial fractures ${ }^{[8]}$.

The aim of current study was to evaluate treatment of open comminuted diaphyseal tibial fracture by ilizarov external fixator; its effective, availability, outcomes and complications.

\section{PATIENTS and METHODS}

This prospective study included a total of 10 patients with comminuted tibial diaphyseal fractures managed with early Ilizarov external fixator, attending at Alharam Hospital. This study was conducted between Feb 2018 and July 2019.

\section{Ethical approval:}

The study protocol was approved by the Hospital Ethics Committee and a written informed consent was obtained from all patients.

The study group included ten patients with open tibial shaft fractures. Their mean age was 28.6 ranging from to 17 and 35 years old, with patients between 17 and 30 years comprising $50 \%$ of the cases. They were all males, who underwent the procedure and completed a minimum follow-up of 17 months, were included in the study.

Inclusion criteria: Gustilo-Anderson types IIIA and IIIB fractures presenting within two days of injury Exclusion criteria: Polytrauma patients, fractures with metaphyseal involvement, types I, II and IIIC fractures.

The right side was involved in 5 and the left side in 5 patients (1:1). Road traffic accident was the most common mode of injury (8 patients), followed by gunshot injury (two). Morphology of the fractures was classified according to the Gustilo-Anderson classification (Table 1). The Gustilo-Anderson classification has been the most widely used system and is generally accepted as the primary classification system for open fractures. This classification system takes into consideration the energy of the fracture injury, soft tissue damage, and the degree of contamination. Types I and II are essentially low energy fractures, while type I has a wound size of 1 $\mathrm{cm}$ and that of type II is more than $1 \mathrm{~cm}$. The classification system has been modified since the original classification to allow a more accurate prognosis for more severe injuries (i.e. type III injuries) ${ }^{[9]}$. In our series, type IIIA fractures were the most common, comprising 8 patients $(80 \%)$, followed by type IIIB with 2 patients (20\%). The middle onethird of tibia was fractured in 7 patients $(70 \%)$, the lower third in $2(20 \%)$ and the upper third in one patient $(10 \%)$. Initial resuscitation, splintage after irrigation and debridment the wound were provided in the emergency room. Any protruding bone fragments were covered with sterile dressing and obvious foreign material removed. The wound was washed with normal saline (6 litres for type IIIA and about 9 litres for type IIIB). Only stay sutures were applied to cover the bone, if possible. To stabilise the fracture, an external fixator was applied. In all cases, $\square$ rd generation cephalosporins and was administered in the emergency room and used till operation. In fractures with soil contamination injuries, metronidazole was added. Definite fixation with the Ilizarov was carried out after within two weeks ranging from day 1 to day 14 of the initial emergency debridement. Pre-assembled frames were used to save surgical time. Four Ilizarov rings were used. We used 1.5 and $1.8-\mathrm{mm}$ Ilizarov wires in all patients. The Schanz pins introduced in the initial fixation were also included in the frame, if possible. When removal of loose unviable small fragments was necessary or where bone loss existed, shortening was done. This shortening was also helpful in closure of wound.We were able to achieve delayed primary wound closure in 4 patients.

\section{Table 1: Gustilo-Anderson classification}

\begin{tabular}{|l|l|l|}
\hline Type & Wound Description & Other criteria \\
\hline I & $\begin{array}{l}<1 \mathrm{~cm} \text { (so-called } \\
\text { puncture wounds) }\end{array}$ & \\
\hline II & $1-10 \mathrm{~cm}$ & $\begin{array}{l}\text { Segmental } \\
\text { fractures, farm } \\
\text { injuries, or any } \\
\text { injury occurring } \\
\text { in a highly } \\
\text { contaminated } \\
\text { environment. } \\
\text { aigh-velocity } \\
\text { gunshot injuries }\end{array}$ \\
\hline IIIB & $\begin{array}{l}\text { 10 cm, requiring soft } \\
\text { tissue coverage } \\
\text { procedure }\end{array}$ & $\begin{array}{l}\text { Periosteal } \\
\text { stripping }\end{array}$ \\
\hline IIIC & & $\begin{array}{l}\text { With vascular } \\
\text { injury requiring } \\
\text { repair }\end{array}$ \\
\hline
\end{tabular}

The average operating time was 1 hour and half minutes, increase in operating time was needed for the comminuted fractures. Antibiotics were continued for five days post-operatively, up to 2 weeks in severe infections. and further if indicated. The patients and their attendants were educated pin site care and how to deal with the frame. On the first post-operative day, ankle and knee mobilization was started according to pain toleration. All patients were made to weight bear with support after 24 hours graded from partial weight bearing to full weight bearing according to tolerance of pain. In patient with shortening distraction was started on the first post-operative day at a rate of $0.25 \mathrm{~mm}$ per day.

The patients were discharged after being taught distraction methods and pin tract care (cleaning at 
least twice a day with alcohol). The average hospital stay of the patients was 9 days (5-17 days). Patients were followed-up regularly, checking for stability of the frame, pin tract condition, loosening, wound condition, ankle and knee range of motion and leg limb discrepancy.

Clinical and radiological assessment of union was done. Whenever required, modification in the frame were made. Compression at the fracture site was performed if no evident of callus formation after 3 weeks. Removal of the frame has been done after appearance of grade $\mathrm{V}$ regenerate in the radiographs according to Fernandez-Estev grading.

When there was evidence of periosteal bridging and obliteration of the fracture line by endosteal callus formation union was considered.

When union appeared to be present the frame was dynamized for a three- to four-week period, then frame removal. Patellar tendon bearing cast was applied for three to four weeks with the patient bearing full weight in cases of delayed callus formation (more than 16 weeks).

The total follow-up took place 17 months. ASAMI criterion was used to evaluate the final results. An excellent result was defined as fracture union with full knee extension and more than $125^{\circ}$ flexion, ankle range of motion $>75 \%$ of normal, limb length discrepancy $<2.5 \mathrm{~cm}$, no angulation $>7^{\circ}$ in any plane, no rotation $>7^{\circ}$ and absence of infection.

A good result indicated fracture union with one criterion missing, and a fair result was fracture union with two criteria missing. A poor result indicated fracture union with three missing criteria or nonunion.

\section{RESULTS}

The study group included ten patients with open tibial shaft fractures. Their mean age was 28.6 ranging from to 17 and 35 years old. They were all males. They had 5 right and 5 left tibial fractures (50\%:50\%). According to the AO Classification, tibial shaft cases were classified as four cases type B2 (40\%), four cases with B3 (40\%), 2 cases C1 (20\%). According to GUSTILLO and ANDERSON Classification, the study included 8 cases type IIIA (80\%), 2 cases type IIIB (20\%). According to GUSTILLO classification, The Study Included 8 Cases Type IIIA (80\%), 2 Cases Type IIIB (20\%). All cases were males. In our study, as all cases were presented as open fractures, a great attention was given to the wound, so immediate debridement of the wound and irrigation, removal of any debris or devitalized tissues. This would not delay more than 6 hours. If any de-gloved flaps of skin were questionable, the unviable portion was removed and the healthy portion was kept for later coverage.

Temporary external fixation was done in the two Type IIIB cases, for allowing plastic intervention, They needed skin flab.

This is Followed by application Of the Ilizarov fixator after one week.The delay time after trauma until frame application ranged from 0-14 days (mean 4.6 days).Return to the Activity of Daily Living (ADL) occurred in all cases in a different manner. None of our patients was using crutches, or a cane. In cases with associated lower extremity fractures weight-bearing is delayed usually for about one month.

Inactivity means (unemployment or inability to return to daily activities because of the leg injury. It is considered as a poor result regardless the other criteria. The most important factor that adversely affects range of motion (ROM) is mounting the fixator into the joint. None of our cases, the fixator is mounted to the knee. Three cases developed ankle stiffness.

The average total range of knee motion in these cases in Our study was 130.5 (range 125-140). Totally the knee ROM wasn't affected by the trauma as there was no need to mount the knee in any of our cases. 


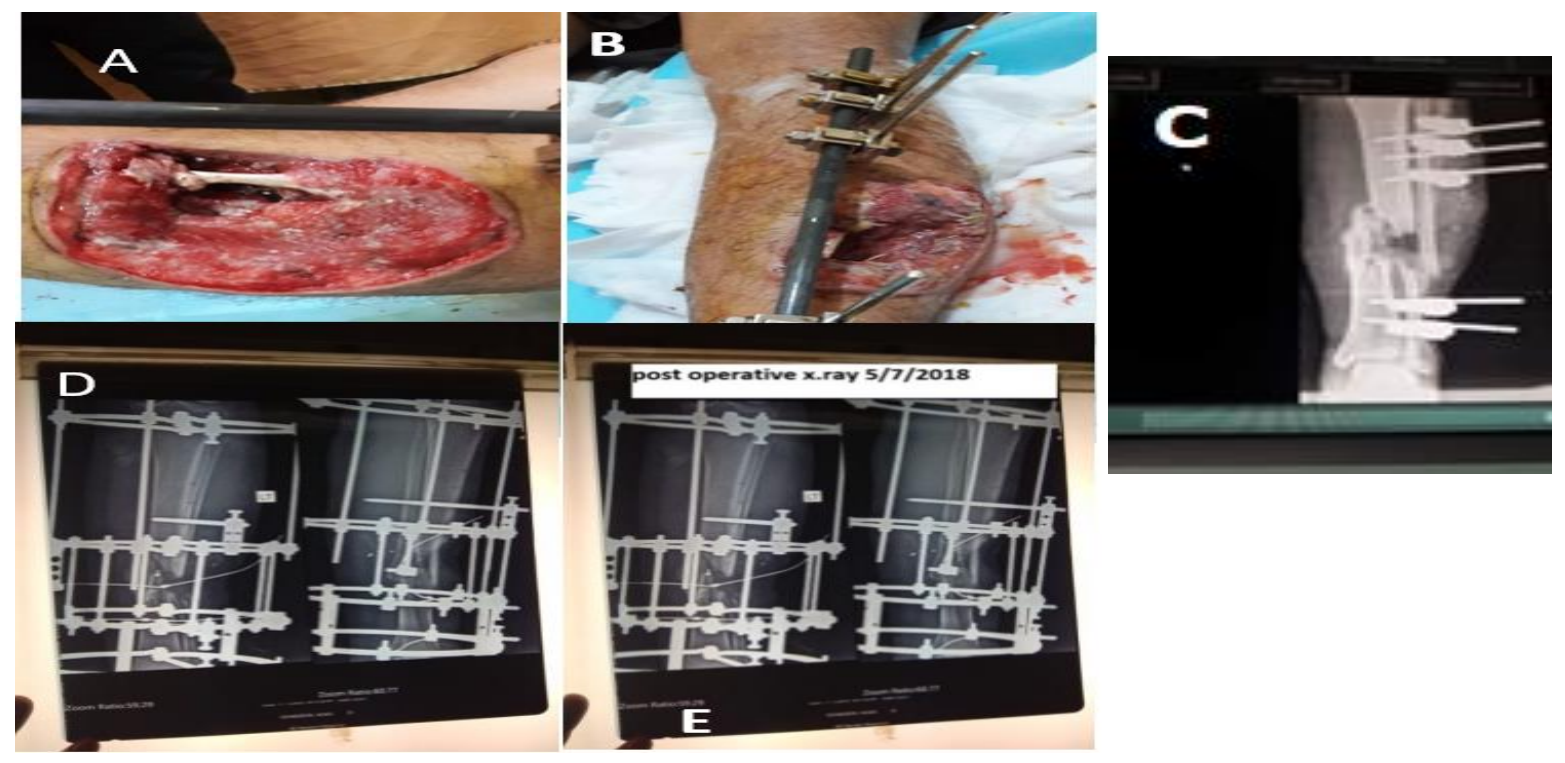

Fig. 1: A \& B showing open G IIIB fixed by ex. fix on admission, C Initial anteroposterior (AP) radiograph shows a comminuted fracture of the tibia and fibula. F Initial radiograph after temporary fixation with external fixator. D \& E Immediate postoperative radiograph.

The ankle joint ROM affected in 3 cases of the study. Three cases with final ROM of the ankle $<75 \%$ of the normal side. A significant limp occurred only in 3 cases, which appears with fatigue or when the patient uses normal shoes without insole to correct the LLD. Causes of limp in our study was due to Shortening $>2.5 \mathrm{~cm}$. NO persistent limp persisted in our cases. The difference in the leg measurement between fractured and normal side (LLD) was present in 7 cases in this study. 3 cases were with $3 \mathrm{~cm}$ difference, while 4 with $2 \mathrm{~cm}$. All of them were able to walk properly with the use of higher heel shoes without the need of walking aids. This shortening was due to the comminution of the fracture which necessitated collapse at the fracture site to speed healing without further operative

procedures. In the 3 cases with $3 \mathrm{~cm}$ shortening, two was presented with bone fragments lost at the time of injury, while the third was done intentionally to perform acute bone shortening after bony debridement and primary soft tissue repair thus avoiding the need for flap coverage. The assessment system of bone used is that used by the ASAMI group ${ }^{[10]}$, this system assesses the bony union, degree of residual deformity, the limb length discrepancy, and the presence of infection. Excellent results were considered when the bone united without infection, deformity less than 7 degrees at any plane, and LLD less than 2.5 in the tibia. Good results occur when the bone united with one criterion missing. Fair results are those when the bone united with the missing of two criteria. While the poor results when the fracture is not united or the presence of complication that required revision. Excellent results are obtained in 4 cases (40\%). Good results are obtained in 3 cases (30\%) with overall good to excellent results is about (70\%).Fair results are obtained in 3 cases $(30 \%)$. The assessment of function we used is that the ASAMI group also. This method assesses the activity, the presence of significant pain, the joint stiffness, reflex sympathetic dystrophy (RSD), and significant limp. Excellent Results are obtained in 2 cases (20\%). Good Results are obtained in 8 cases $(80 \%)$.So overall Good to Excellent results are obtained in 10 cases.

The procedure was associated with a number of complications. However, most of these complications were mild. Pin tract infection was the most common complication associated with the procedure, observed in 7 patients. Only one patient has grade IV infections (Moore \& Dahl classification) which required systemic antibiotics, and removal was done in one patient. The rest of the patients had mild infections (grade II in 4 and grade 4 in seven patients) which all healed after pin- site dressings and local antibiotics. Grade V (osteolysis) and VI (ring sequestrum) infections were not observed in any patient. Fifteen patients had mild pain at the fracture site which was managed by analgesics and subsided. 2 patients had an erythrmatous reaction around the pin tract which responded to medications. None of the patients had refracture. Loss of longitudinal height occurred in ten cases in our study. 3 cases with $1 \mathrm{~cm}$ shortening, 4 cases with $2 \mathrm{~cm}$ shortening and 3 cases with $3 \mathrm{~cm}$ shortening. Total shortening ranged from $1-3 \mathrm{~cm}$, intended acute shortening in three cases was done to achieve union and to obtain delayed-primary wound repair without the need for local flap. This Shortening of 1 to $3 \mathrm{~cm}$ didn't affect much the final outcome of the patients who used higher heel shoes. 


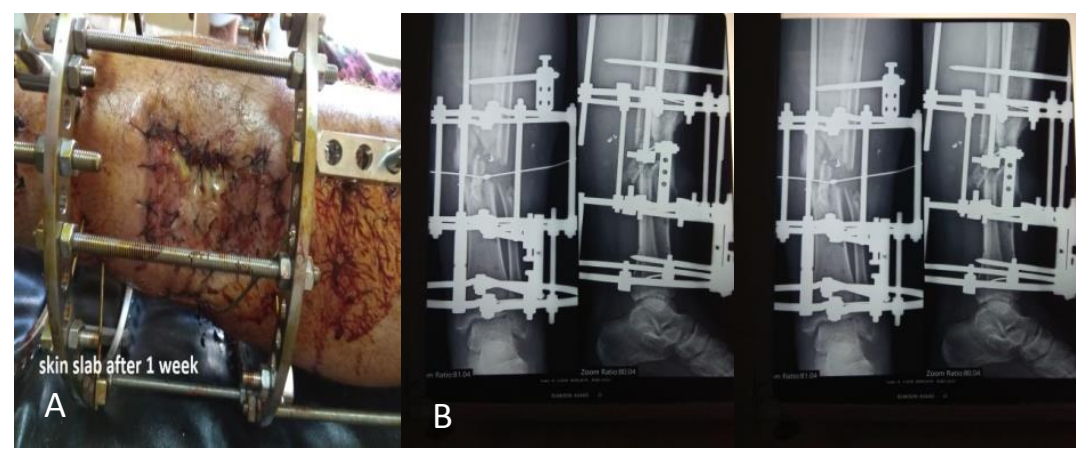

Fig (2): a skin graft after 1 week of frame application, b\&c radiological x.ray after one month.

heels to correct LLD. Signiant pain occurred in three cases in our study.it occurred usually after increasing activity, in two cases pain was relieved by NSAIDs. Third case, pain persisted significantly despite NSAIDs.Joint stiffness occurred in 3 cases in our study, with distal tibial shaft fractures developed ankle stiffness this occurred due to extension of fixation into the ankle for increasing stability of the fixation as the distal segment of the shaft permitted only one ring. The total ROM of these cases reached less than half of the opposite ankle.

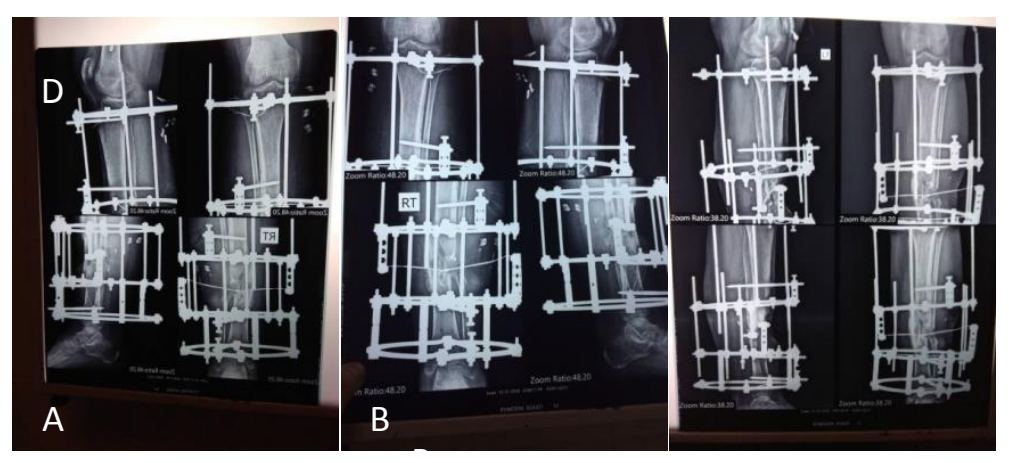

Fig (3): A \& B radiographic x-rays at 3 months, C full dynamization of frame at 4 months.

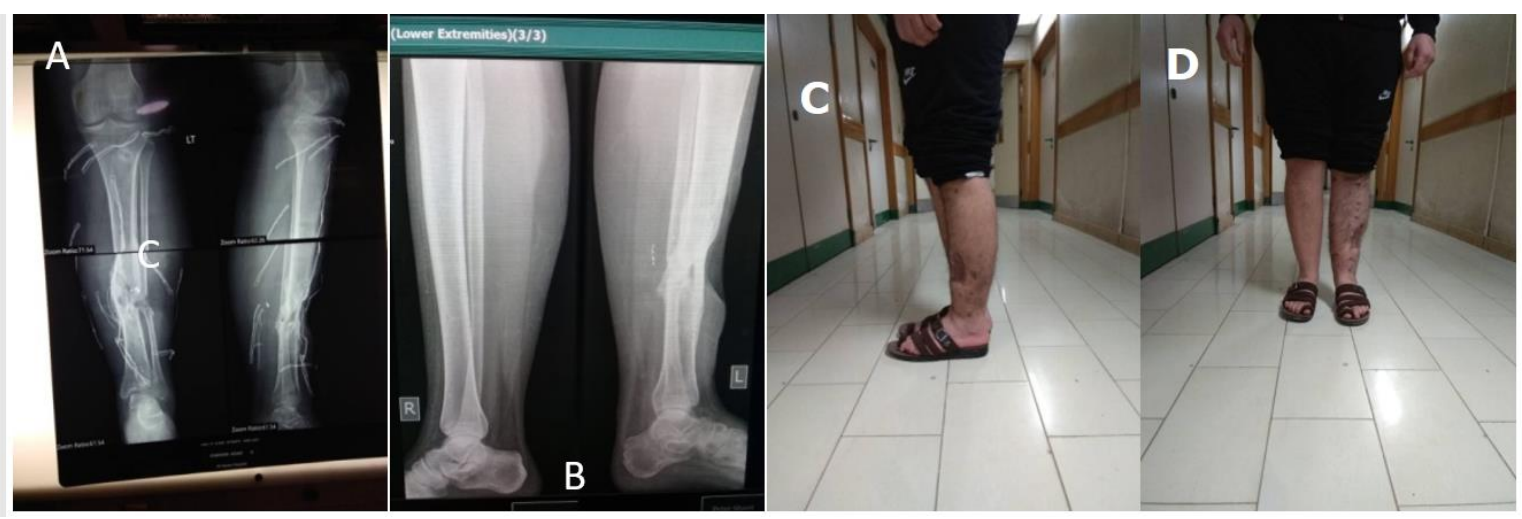

Fig (4): A shows immediate $x$-rays after frame removal, B x-rays 2 weeks after removal full union, C\&D patient standing.

\section{DISCUSSION}

Open diaphyseal tibial shaft fractures are the most common open fractures involving the long bones with an annual incidence of 5.6 per 100,000 persons ${ }^{[11]}$. The rocky blood supply and lack of soft tissue cover of the shaft of the tibia make these fractures liable to non-union and infection ${ }^{[12]}$.

The acceptable goals for open diaphyseal comminuted tibial fractures remains the prevention of infection; keeping of normal length, rotation and alignment of the extremity; minimizing further damage to soft tissue and bone; preserving the remaining circulation and providing a mechanical environment which stimulates periosteal and endosteal responses which induce bone healing ${ }^{[13]}$. Plate fixation, especially in communited fractures is associated with a number of complications, A systemic review of eleven studies involving 492 open diaphyseal comminuted tibial fractures managed by plating revealed a revision rate ranging from $8-69 \%$ 
and a bundled estimate of deep infection rate of $11 \%$ [14]. Sigvard and Allan reported severe infections in $19 \%$ of the open diaphyseal tibial fractures treated by plate fixation ${ }^{[15]}$. External fixation has been popular because of the relative ease of application and minimally invasive wires but these advantages have been outweighed by the high incidence pin-track infection, difficulties relating to soft-tissue management and the potential for malunion. Papaioannou et al. reported pin tract infection in 20 $\%$ of patients with open diaphyseal tibial fractures managed by external fixators, especially types II and III ${ }^{[16]}$. Primary intramedullary nailing has gained wide acceptance in open tibial fractures ${ }^{[17]}$. But associated with high infection rate. (especially in type IIIB fractures) and delayed union [18]. Although reports have shown good results with IM nailing, extending these to developing countries, where patients comes late and adequate facilities unavailable ${ }^{[19]}$.

Intramedullary nailing in fractures initially treated by external fixation has been associated with a high rate of infection, especially when external fixation was associated with pin track infection ${ }^{[20]}$. Joshi et al. had an infection rate of $10.7 \%$ in open tibial diaphyseal tibial fractures managed by unreamed nailing, even after debridement and adequate soft tissue coverage [21]. They did not recommend nailing in type III fractures.

The Ilizarov device has been used in open tibial fractures mostly as a salvage procedure for the complications arising from other treatment methods ${ }^{[22]}$. Recently, it has been used as the primary and a definitive management in open fractures in many centers throughout the world, especially Russia and Western Europe ${ }^{[23]}$. Ilizarov combines the attributes of early weight bearing and a solid fixation with adequate management of the wounds while at the same time addressing the bone loss. Ilizarov provides effective and safe treatment modality for open diaphyseal comminuted tibial fractures. The hallmark of the method is the high union rate.

Hosny and Fadel achieved union in all 34 open tibial fractures managed by Ilizarov ${ }^{[24]}$. Sidharthan et al. got union in 42 high energy comminuted diaphyseal tibial fractures managed with Ilizarov and advised the using Ilizarov in high energy comminuted diaphyseal tibial fractures ${ }^{[25]}$. We also got union in all the 10 open tibial fractures managed by Ilizarov. All fractures united without any perisitent infections. The high rate of union with Ilizarov could be due to the minimally invasive wires which leads to minimal stripping of the soft tissues and the consequent interference with the vascularity of the bone and the fracture. This is in compare to intramedullary nailing which disrupt with the intramedullary circulation.

The disruption of circulation is seen with both reamed and unreamed intramedullay nailing, despite the degree of compromise is a matter of controversy [26]. The time to achieve union with Ilizarov varies in different studies, since different authors have used measures of union. Bone union reported by Inan $\boldsymbol{e t}$ al. in 19 weeks in all type IIIA diaphyseal tibial fractures and the time to union was less than in the nailing group ${ }^{[27]}$.

The time to union in our patients is comparable to that of Tucker who used the same criteria as we did for defining union. The union time in type IIIB patients without bone loss is not significantly different from that in type IIIA. However, when fractures with bone loss are also included the difference in union time when compared with type IIIA fractures becomes significant. This may be related to the severity of trauma which leads to soft tissue damage and loss of blood supply to the bone. A significant difference between types IIIA and IIIB was found in time to union ${ }^{[27]}$.

The average union time in patients with bone loss in our study was directly related to the bone defect. Dagher and Roukoz did not find any correlation between defect length and union time ${ }^{[28]}$. Despite, most of their patients had already undergone other surgeries before Ilizarov, unlike our patients, in which all patients had Ilizarov as the primary and definitive treatment. The healing index of 1.52 months/ $\mathrm{cm}$ seen in our patients is similar to that reported by Dendrios (1.78 months/cm) ${ }^{[29]}$.

Soft tissue management holds the key to achieving a good functional result in open diaphyseal comminuted tibial fractures. The timing of soft tissue coverage is controversial, the standard teaching being repeated irrigation and debridement of all dead tissues before wound suturing ${ }^{[30]}$. This recommendation has been recently challenged, with authors advocating primary closure of open wounds in some cases.

Shtarker et al. reported a good result after primary suturing and Ilizarov fixation in the treatment of open diaphyseal comminuted tibial fractures ${ }^{[31]}$. A good results in type IIIB fractures with immediate fracture fixation and wound debridement and coverage (using free muscle flap or pedicled) has been reported by De Long et al. ${ }^{[32]}$.

In healthy adults, wound healing heels in the first 5 days or so regardless of whether the wound is closed. Thus, delayed suture in wounds within five days is able to achieve wound strength by the end of the second week ${ }^{[33]}$. Since we applied Ilizarov after three to five days of the initial debridement, we were able to achieve wound closure in the majority of type IIIA fractures at the time of Ilizarov application. The number of additional procedures required to achieve wound coverage (superficial skin graft or musculocutaneous flaps in type IIIB fractures) is thus reduced by the use of Ilizarov after three to five days of the injury.The overall number of secondary procedures required with IEF is less compared to 
other methodes. Wound coverage procedures constitute the bulk of secondary procedures with Ilizarov. No wires or pins was needed to be replaced. In contrast, nailing is associated with, infections a risk of non-union and malunion, needing additional surgeries. Plus, nailing is associated with a significant risk of infection by negatively influencing the intramedullary circulation, although the effect of reaming on infection is controversial. The Ilizarov device is minimally invasive and compatible with the biology of fracture. This leads to decreased incidence of non-union and infection. In addition to decreased number of secondary procedures which decreases repeated admissions and don't entail the occupancy of hospital beds and a financial burden to the patient. Ilizarov permits early weight bearing of the patient within the limits of pain.

This produces axial compressive forces at the fracture site which is a must for bone healing. Despite being less stiff in the axial compression, IEF is moderately to highly stiff in AP and lateral bending strains. Ilizarov wires provide multiple cortical interfaces and the multiplanar orientation of the wires virtually eliminates any late displacement of fragments leading to a low rate of malunion.

An Ilizarov fixator also enables the surgeon to correct any deformities arising during the course of treatment. IEF is also associated with a number of complications, although most of these are little and controlable. Pin site infections considered the bulk of complications associated with Ilizarov ${ }^{[33]}$. Although most of cases were superficial, infection increases the risk of wire loosening and frame instability.

Good care of pin tract and well management of superficial infections is essential to prevent osteomylities and septic knee (associated with wires placed less than $1 \mathrm{~cm}$ from the subchondral bone). Insufficient pin site care has been associated with higher rates of pin site problems ${ }^{[34]}$.

Muscle contracture and joint stiffness are significant problems, especially seen in patients where fixator is applied for prolonged periods and in fractures near the joints ${ }^{[35]}$. Vigorous and Early range of motion help in achieving a good functional outcome. Refracture is a troublesome complication, which not seen in our serious. ${ }^{[27]}$.

Inan $M$ et al. reported up to $8 \%$ of his cases. These fractures usually arise due to early removal of the frame. Malunion,is less common with IEF which is a frequent complication with nailing. IEF allows the surgeon to correct deformities while the bone is undergoing lengthening or union.

\section{CONCLUSION}

Ilizarov external fixator is the best way for management of open diaphyseal comminuted tibial shaft fracture in comparison to other methods of fixation. In spite of little number of patients with short term follow up treatment complications which was minors.so we recommend treatment of open diaphyseal comminuted tibial shaft fractures by Ilizarov with further studies on large number of patient and long term follow up.

\section{REFERENCES}

1.Lua JY, Tan VH, Sivasubramanian H, Kwek E (2017): Complications of Open Tibial Fracture Management: Risk Factors and Treatment. Malaysian Orthopaedic Journal ,11 (1): 18-19.

2.Newman SD, Mauffrey CP, Krikler S(2011): Distal metadiaphyseal tibial fractures. Injury, 42(10):975-84.

3.Mukherjee S, Arambam MS, Waikhom S, Santosha, Masatwar PV, Maske R (2017): Interlocking Nailing Versus Plating in Tibial Shaft Fractures in Adults: A Comparative Study. J Clin Diagn Res ., 11(4):RC08RC13.

4.Foote CJ, Guyatt GH, Bhsc KNV, Mundi R, Chaudhry H,Heels-ansdell D (2015): Which Surgical Treatment for Open Tibial Shaft Fractures Results in the Fewest Reoperations ? A Network Meta-analysis. Clin Orthop Relat Res ., 2179-92.

5.Bhandari M, Guyatt G, Tornetta P, Schemitsch EH, Swiontkowski M et al. (2008) : Randomized trial of reamed and unreamed intramedullary nailing of tibial shaft fractures. J Bone Joint Surg Am., 90(12):2567-78.

6.Bilal D, Sami S, Erdem Ö, Umut Y, Serda D, Yavuz $\mathbf{S}(\mathbf{2 0 1 3})$ : new application technique of circular fixator for the treatment of open tibial fractures: circular fixator-hinge technique.Ulus Travma Acil Cerr Derg .,19(6):543-547 .

7.Yongchuan L, Xi J, Qinghe G et al. (2014) : Treatment of distal tibial shaft fractures by three different surgical methods: a randomized, prospective study International Orthopaedics (SICOT) ,38:1261-1267.

8. Tirth V, Hiren S, Aalok S et al. (2017) : Retrospective study of open tibial diaphyseal fractures, type IIIA and IIIB by Ilizarov method IJOS ., 3(2): 507-512@ IJOS.

9.Coles CP, Gross M (2000) : management and treatment complications. A review of the prospective literature. Can J Surg ., 43(4):256-62.

10. Fleming B, Paley D, Kristiansen T, Pope M (1989): A biomechanical analysis of Ilizarov external fixator. Clin Orthop., 241: 19.

11.Court-Brown CM, Rimmer S, Prakash U et al. (1998) : The epidemiology of open long bone fractures. Injury, 29:529-534.

12.Esterhai JL, Queenan J (1991) : Management of soft tissue wounds associated with type III open fractures. Orthop Clin North Am., 22:427-432.

13.Tucker HL, Kendra JC, Kinnebrew TE (1992) : Management of unstable open and closed fractures using the Ilizarov method. Clin Orthop., 280:125-135.

14.Giannoudis PV, Papakostidis C, Kouvidis G, Kanakaris NK (2009) : The role of plating in the operative treatment of severe open tibial fractures: a systematic review. Int Orthop., 33(1):19-26.

15.Bach AW, Hansen ST (1989) : Plates versus external fixation in severe open tibial shaft fractures. A randomized trial. Clin Orthop Relat Res., 241:89-94. 
16.Papaioannou N, Mastrokalos D, Papagelopoulos PJ et al. (2001) : Non-union after primary treatment of tibia fractures with external fixation. Eur J Orthop Surg Trauma, 11:231-235.

17.Finkemeier CG, Schmidt AH, Kyle RF, Templeman DC (2000) : A prospective, randomized study of intramedullary nails inserted with and without reaming for the treatment of open and closed fractures of the tibial shaft. J Orthop Trauma, 14:187-193.

18.Hupel TM, Weinberg JA, Aksenov SA, Schemitsch EH (2001) : Effect of unreamed, limited reamed and standard reamed intramedullary nailing on cortical bone porosity and new bone formation. J Orthop Trauma, $15: 18-27$.

19.Kuhn S, Hansen M, Rommens PM (2007) : Extending the indication of intramedullary nailing of tibial fractures. Eur J Trauma Emerg Surg., 2:159-168.

20.Maurer DJ, Merkow RL, Gustilo RB (1989) : Infection after intra- medullary nailing of severe open tibial fractures initially treated with external fixation. $\mathbf{J}$ Bone Joint Surg Am., 71(6):835-838.

21.Joshi D, Ahmed A, Krishna L, Lal Y (2004) : Unreamed interlocking nailing in open fractures of tibia. J Orthop Surg .,12 (2):216-221.

22.Lalit M, Manish C, Jashan V, Kapoor S, Mehtani A, Dhaon BK (2000) : The Ilizarov method in infected non-union of fractures. Injury, 31(7):509-517.

23.Ilizarov GA (1989) :Experimental studies of bone elongation. In: Coombs R, Green S, Sarmiento A (eds) External fixation and functional bracing. Orthotext, London, p 375.

24.Hosny G, Fadel M (2003) : Ilizarov external fixator for open fractures of the tibial shaft. Int Orthop., 27(5):303-306.

25.Sidharthan S, Sujith A, Rathod AK, Pathak RH (2005) : Management of high energy tibial fractures using the Ilizarov apparatus. Internet J Orthop Surg., 2:2.
26.Ziran BH, Darowish M, Klatt BA, Agudelo JF, Smith WR (2004) : Intramedullary nailing in open tibia fractures: a comparison of two techniques. Int Orthop., 28(4):235-238.

27.Inan M, Tuncel M, Karaoğlu S, Halici M (2002) :Treatment of type II and III open tibial fractures with Ilizarov external fixation. Acta Orthop Traumatol Turc., 36(5):390-396.

28.Dagher F, Roukoz S (1991) : Compound tibial fractures with bone loss treated by Ilizarov technique. J Bone Joint Surg Br .,73:316-321.

29.Dendrios GK, Kontos S, Cyritsis E (1995) : Use of Ilizarov technique for non-union of tibia associated with infection. J Bone Joint Surg Am., 77(6):835-846.

30.Cierny G, Byrd HS, Jones RE (1983) : Primary versus delayed soft- tissue coverage for severe open tibial shaft fractures. Clin Orthop., 178:54-63.

31.Shtarker H, David R, Stolero J, Grimberg B, Soundry M (1997) : Treatment of open tibial fractures with primary suture and Ilizarov fixation. Clin Orthop., 335:268-274.

32.Delong WG Jr, Born CT, Wei SY, Petrik ME, Ponzio R, Schwab CW (1999) : Aggressive treatment of 119 open fracture wounds. J Trauma, 46:1049-1054.

33.Olson SA, Finkemeier CG, Moehring HD (2001) : Open fractures. In: Bucholz RW, Heckman JD (eds). Rockwood and Green's fractures in adults, 5th edn. Lippincott Williams \& Wilkins, pp 285-318.

34. Thayur RM, Balasundaram R, Manjunath KS et al. (2008) : Outcomes of Ilizarov ring fixation in recalcitrant infected tibial non-unions - a prospective study. J Trauma Manag Outcomes, 2:6.

35.Inan M, Halici M, Ayan I, Tuncel M, Karaoglu S (2007) : Treatment of type IIIA open fractures of tibial shaft with Ilizarov external fixator versus unreamed tibial nailing. Arch Orthop Trauma Surg., 127(8):617623. 